\title{
The 'Hyphenized' Identity in Chinese Diaspora in the Works by Chin Shun-Shin, Higashiyama Akira, and Ed Lin
}

\author{
Masami Usui
}

\begin{abstract}
The 'hyphenized' identity represents the multiracial, multicultural, and transnational identity in the age of globalization. Because of its historical background, Taiwan has been producing the unique literature of hybridity, and is also blessed with the new wave of Taiwanese-Chinese-Japanese / Taiwanese-American literature, represented by Chin Shunshin (陳舜臣), Higashiyama Akira (王震緒), and Ed Lin across China, Taiwan, and Chinatown. The 'hyphenized' identity consists of triple-layered passages: Chin's coverage from his early mystery novels set in Kobe's Chinatown in the1970's to his Chinese historical novels, Higashiyama's journey back to the 1970 Taipei in his award-winning novel Ryu, and Lin's shift from his 1970 New York Chinatown crime novels to his new trial to embark on contemporary Taipei night market in Ghost Month. Mapping the landscapes of China, and Taiwan, and Chinatown in those works is compiled by examining the mythological space of China and Taiwan, the ideological discourse in the 1970's, and the hybrid sphere of Chinatown. Consequently, the 'hyphenized' identity in Chinese Diaspora embodies a quest for the transforming and newly-establishing space and self.
\end{abstract}

Index Terms-Chinese diaspora, Taiwanese literature, comparative literature.

\section{INTRODUCTION}

The "hyphenized" identity represents the multiracial, multicultural, and transnational identity in the globalized era The globalized era is broken into pieces and confronted with the rapidly transforming enormous catastrophes on this planet since most of consequences of globalization result in more complicated political, economic, environmental, social, cultural, and religious catastrophes. Because of its historical background, Taiwan has been producing the literatures in Taiwanese, Chinese, and Japanese (Fujii 12) [1]. In addition, the writers from Taiwan have published their works outside Taiwan in their new settlements such as Malaysia, Japan and US. Taiwanese literature, thus, embodies a hybrid globalization. In this borderless era due to globalization, there are more heated conflicts on terrorists, national territorials, racial conflicts, hate crimes, and rapidlywounded environmental conditions leading to natural disasters. In a process of shaping to a globalized nation, Taiwan has undergone all the consequences of aboriginal oppression, colonization, decolonization, one-party military regime, democratization, and industrialization. Taiwan as the microcosm of these multilayered catastrophes is targeted by such "hyphenized" writers as Chin Shun-shin (19422015), Akira Higashiyama (1968-), and Ed Lin.

Manuscript received September 5, 2015; revised March 1, 2016.

M. Usui is with the Doshisha University, Kyoto, Japan (e-mail musui@mail.doshisha.ac.jp)
In this era of shared catastrophes, the "hyphenized" identity becomes more important and meaningful to present to us the new possible path to comprehending the concealed and muted stories behind histories. As a TaiwaneseJapanese, Chin was born of Taiwanese Islanders in Kobe, Japan, received higher education in Japan, and kept his dual nationality till his death. Higashiyama was born of Taiwanese Mainlanders in Taipei, settled and received higher education in Fukuoka, Japan after drifting between two countries, and possesses his Taiwanese nationality and his Japanese penname. Belonging to the younger generation, Lin is a native New Yorker born of Chinese-Taiwanese parents and has been working and living there. In their crime novels, their protagonists / writers' alter egos travel from China, Taiwan, Chinatowns in such cities as Kobe and New York, etc. The local / global spheres are intertwined with the colonial / postcolonial discourses. In this intertwined space, moreover, mystery / crime novels reflect the profound aspects of humanity. Unlike the mainstream literature, crime novels in Taiwan had certain characteristics especially during the years of the Japanese Occupation (Nakajima 393) [2]. Among the crime novel writers, therefore, Chin, Higashiyama, and Lin demonstrate the once-muted selves that were victimized in the civil war and colonial years, transported to the different shores, transplanted in the alien soils, confronted with another victimization on route to assimilation, and ultimately resolved into the sanctuary of diversity. No matter how different their generations and backgrounds may be, their consciousness as "hyphenized" writers can be examined in their mapping landscapes, their tracing histories, and their recording stories.

\section{MAPPING LANDSCAPES - ChINA, TAIWAN, AND CHINATOWN}

For those three writers, Taiwan is geographically the common land of the family history, yet it does not entirely represent their identity. Since the thirteenth and fourteenth centuries till now, Chinese emigration has been continuing with different reasons in various types and those overseas Chinese signify Chinese Diaspora. In this discourse of diaspora, however, Taiwan symbolizes the rest station between their regional home town in China and their global residential area outside China. Their local identity represented by their dialects is confronted with their global identity represented by Mandarin and possibly English as well as the other languages of their new residential area such as Japanese. Their life styles and sense of values are gradually transfigured even though they possess the consistent shared beliefs in Taoism and Confucianism 
within the family and community circles. The process of establishing the "hyphenized" identity is formulated by that of mapping the transfigured landscapes from China, Taiwan, and Chinatown.

\section{A. The Mythological Space of China and Taiwan}

For those writers, China has dual meanings: the ancient China is a pride, while the communist China is a trouble. China is the roots for overseas Chinese since China as a general term represents the great Chinese continent with the background of ancient civilization. The roots in China is a pride for overseas Chinese. Chin's early crime novels, for example, represent the overseas Chinese' connection to China before

World War II. Being himself a Chinese descent from Henan and Fujian, Chin is proud of his ancestors and their family background as the Islanders (本省人) who emigrated to Taiwan possibly during the Quin Dynasty. The private detective in a series of Chin's early crime novels is Tou Ten bun (陶展文) who was brought up in Fujian where his father had been transferred as a public civilian. His strong inclination to completing his lifelong work to write a series of historical novels ranging from Sanguo Zhi (三国志) to Sun Yat-sen(孫文) expresses his consistent pride in his Chinese ancestry dating back to Wei Chih (魏志) [3]. China's grand-scale history is the ground for the core for Chin's creative activities (Liao 79-80) [4]. Different from Chin's China, Higashiyama's China is a communist nation. His Naoki prize-winning novel, Ryu [The Stream] (2015), starts and ends with the protagonist's journey to China to discover the mystery connected with the Mainlanders (外省 人) [5]. The protagonist, Ie Chu-shen (葉秋生) at seventeen in 1975 gradually unveils his grandfather Ie Zun-rin's involvement in massacre in China in 1943 during World War II. Zun-rin's secretly-kept gun that represents his aggression, however, misleads Chu-shen to a wrong direction; however, he ultimately discovers that his grandfather's favorite yet adopted son, Yui Uein, killed him because he had killed Uein's communist parents in the massacre in China. China during the age of Japanese colonization changed the destiny of Ie family because of the political conflict between communists and nationalists.

\section{B. The Ideological Discourse in the 1970's}

The 1970's is a crucial era for Taiwanese descents in Taiwan, Japan, and US in a process of settlement, assimilation, and naturalization (Ichikawa 117-19) [6]. Taiwan's politically and socially unstable conditions influenced the Taiwanese descents outside Taiwan. Regarding nationality, there is a conflict regarding the political issues between the Republic of China and People's Republic of China especially after World War II. Due to the Japanese government strategy to the common national naming "China" to avoid the political conflicts between the Republic of China and People's Republic China (何) [7], Chin's Taiwanese nationality had to be switched to that of China after World War II; yet he abandoned its nationality to resist against the Tiananmen Incident in 1989, and kept his dual Japanese / Taiwanese nationality. As for the relationship between Taiwan and Japan, moreover, Islanders sent their children to study in Japan before WWII during the Japanese Occupation of Taiwan between 1895 and 1954. Though in a colonial oppression, Taiwanese settlement in Japan before the war embodies the intellectual, economic, and social success. Two Taiwanese, Naoki prize winners, Kyu Ei-kan and Cin, expressed their unsatisfied lives in Japan in the intellectual level. After World War II, however, due to their racial and national background, they were deprived of the chances of establishing themselves in Japanese society. In addition, they belong to the generation in which they have never decided their identity by themselves as Kyu remarks (Kleeman 6-7) [8]. In the 1950's, Tou at his 50's in Chin's novels suffers the loss of his social status and also that of identity as shown in the fact that he has already settled in Kobe, marries a Japanese woman, and owns a Chinese restaurant [9].

Chin's mystery novels covering from the 1950's to the 1970's describe the struggle, settlement, and transformation during the postwar period when Japan was rapidly recovering from the economic depression, yet they were blessed with a series of new trends such as "Chinese boom" in Japan, "Asian Identity," and ethnic boom in an international level (Liao 80). During the same period, Taiwan underwent a series of changes ranging from decolonization, the retreat of the Chinese Nationalists from China to Taiwan in 1949 , the military dictatorship, to the rapid industrialization and economic development (Thornber 85) [10]. Higashiyama's Chu-shen is confronted with the family tragedy and attempts to discover the family myth when his grandfather, Zun-rin, is murdered in a small local retail store. The novel is set in 1975 when Jiang Jieshi died and its turning point in Taiwan leads to his grandfather's death on the next day. For the first generation of Mainlanders, China is the land of their identity before emigration. For the younger generation who are born in Taiwan, China is the country of the family myth constructed in the middle of political conflicts. In contrast to Taiwanese Japanese, Taiwanese in the US settled and owned the family small business and sent their US-born and naturalized children to college. Before the Asian American activism in late 1970's, 1975 was the wake of Asian American's revolt against racial discrimination and prejudice. Higashiyama's inclination to Taipei in 1975 and China during World War II, Lin's new trial to set up his new novel, Ghost Month (2014), in contemporary Taipei [11]. Away from his 1970's New York Chinatown trilogy, Lin discovers that contemporary Taiwan possesses the shadow of the 1970's New York and well-educated Taiwanese Americans are easily victimized in the dark part of the society. Taiwanese American Jin-nan's search for the mysterious death of his former girlfriend is mingled with the crowds of the night market as the representative of Taiwan's growing yet dangerous part, and it is also with the Chinese tradition of the season of the dead spirits, so that the novel is colored by a cultural and social hybridity of Taiwan and America. The 1970's is a crucial era for Taiwanese because of Taiwan's domestic and international political conflicts and social instability.

\section{The Hybrid Sphere of Chinatown}

Located outside China and Taiwan, Chinatown is more "hyphenized" and transformed from the segregated ghetto of 
Chinese immigrants to the developed microcosm of globalization. Since the 1980's, Chinatowns have represented a tourists' attraction by affluent Chinese restaurants and such Chinese festivals and rituals, and by the establishment of the Chinese heritage museums (Zhang 15354) [12], yet it is still now accepting the newly-arrived Chinese as laborers. This transforming sphere is the significant landscape that largely influences the energy of creative activities for the artists. In a socio- and poligeographical context, Chinatowns in the Eastern Hemisphere, Japan has a longer history than those in the American continents. As a hometown for Chin, Nanjin machi (南京町) in Kobe, international port town, was an enclosed area where the Chinese settlers from Quin were forced to live in 1868. After the total destruction of World War II and the other disasters such as Hanshin Great Earthquake, Nanjin machi is reconstructed each time and finally recognized as one of the most popular Chinatowns. As described in Chin's novels, Nanjin machi demonstrates the Chinese success in business and their business is virtually connected to the other Chinese business in Taiwan, Singapore, and other Chinese settlements. Less known than Nagasaki Chinatown, Kyushu, Tojingai (唐人街) in Fukuoka is the oldest Chinatown in Japan and it was officially segregated and recorded in 1627 (Fukuoka UNESCO Society) [13]. Located near Taiwan and China across the sea, Kyushu has a distinct characteristic of overseas commerce throughout its history. Higashiyama confesses that he was unstable between two countries, but he grew up in a multicultural and multiracial community in Japan ("Interview") [14]. This experience of living in Kyushu is the ground of building up his own literature. New York Chinatown, as well as Los Angeles Chinatown and San Francisco Chinatown, embodies the most remarkable example of Chinese settlement in the Western Hemisphere. After the major Chinese immigration during the gold rush in the 1840's, the Chinese slums were built up until the 1880's in Lower East Manhattan (Zhou Chinatown, 6) [15]. Even after the intense racial discrimination and segregation represented by the Chinese Exclusion Act in 1882, however, "nearly 1.8 million immigrants were admitted to the United States from China, Hong Kong, and Taiwan as permanent residents between 1960 and 2006" (Zhou Contemporary Chinese America, 43) [16], so that Chinatowns and its Chinese community have been established expanding in various parts of the US. Especially the "large influx of immigrants from Taiwan since 1965 has led to a noticeable Taiwanese presence" in the US and there appeared large communities throughout the US ( $\mathrm{Ng} 21$ ) [17]. Lin's trilogy is set in New York Chinatown in the 1970's that represents the racial and gender conflicts as the shared experiences for immigrants of Chinese descent. His protagonist, Robert Chow, the landscapes of Chinatown, and New York are formed by local gangs' violence and crimes and also by the political conflicts caused by the US relationship to China and Taiwan. As a town of ambition and desire, Chinatown demonstrates the ghetto of crimes such as Chinese Mafia, underground government, illegal business, prostitution, gambling: at the same time, Chinatown is the shared hometown for the residents of Taiwanese and Chinese descent. From a temporal-resident foreigner to a permanent settler, assimilation is expected and even assigned, yet the newly-awakened "hyphenized" identity forms the new wave of literature.

\section{CONCLUSION}

The 'hyphenized' identity in Chinese diaspora in the works by Chin Shun-shin, Higashiyama Akira, and Ed Lin proves the emerging new power of Taiwanese literature as a globalized literature. With a complicated racial, cultural, and historical background, literatures in Taiwan have been discussed with multiple perspectives throughout its history. Literature based by those who have Taiwanese origin or background has had a trial because it was neglected so that it can be evaluated with a larger and more comprehensive perspective. Literatures in Taiwan during the Japanese imperial and colonial invation is more or less a product of imperialism and colonialism even though such a literary trend as modernism was introduced and spread. The postwar literary scene in Taiwan was again faced with a force from China. Generally discussed from a Japanese view, therefore, both Chin and Higashiyama have to be examined from a Taiwanese and more comprehensive view. Similarly, Lin, as an American writer, needs to be argued from a Taiwanese perspective. By building up the multilayered ground of literature, it is possible to draw a new map of literature among China, Taiwan, Japan, and US. The "hyphenized" writers are blessed with their multiple viewpoints and stories that formulate the new voice of the literature of globalization.

\section{ACKNOWLEDGEMENT}

This paper is one of the products of my five-year (20142018) project entitled "Passage to the Borderless Intellectual Property: In Search for Coexisting Discourse of Global Culture and Literature" (No.26370301) with the Grant-inAid for Scientific Research (c) by Japan Society for the Promotion of Science.

\section{REFERENCES}

[1] S. Fujii, "The creole characteristics in Taiwanese culture," in Lectures on Taiwanese Literature, S. Fujii, et al. Eds. Tokyo: Kokusho Kankokai, 2003, pp. 10-39.

[2] T. Nakajima, The Collection of Taiwanese Crime Novels, Tokyo: Ryokuei Shobo, 2002.

[3] S. Chin, Sonbun, Tokyo: Chuo Koron, 2006.

[4] C. Liao, "The pedigree of 'Japanese-Chinese literature' and the Chinese society in Japan with a focus on the literature of new Chinese migrants," Journal of Chinese Overseas Studies, vol. 1, pp. 74-96, September 2004

[5] A. Higashiyama, The Stream, Tokyo: Kodansha, 2015.

[6] N. Ichikawa, The Analysis of Transformation of Chinese Descents in South East Asia, Fukuoka: Kyushu University Press, 1991.

[7] Y. Q. He, “'Taiwanese Japanese' and break-off of Japan and China relation," The 2012 Report of International Relationship Association Fellowship Project, Jan. 2013.

[8] Y. Kleeman, The Creole in the Japanese Empire, Y. Hayashi, Trans. Tokyo: Keio UP, 2007.

[9] S. Chin, The Roots of the Faded Weeds, 1961, Tokyo; Shueisha, 2009.

[10] K. L. Thornber, Ecoambuity: Environmental Crises and East Asian Literatures, Ann Arbor: University of Michigan Press, 2012.

[11] E. Lin, Ghost Month, New York: Soho Press, 2014.

[12] Y. Zhang, "The display of ethnic identity through a cultural presentation: The case of Kobe overseas Chinese history museum," Forum of International Development Studies, vol. 29, pp. 153-171, Mar. 2005. 
[13] Fukuoka UNESCO Society, Foreign Cultures and Kyushu, Tokyo: Heibonsha, 1973.

[14] Interview of Naoki prize winning novel Ryu between Ijuin Shizuka and Higashiyama Akira, Contemporary Business Weekly, 16 August 2015.

[15] M. Zhou, Chinatown: The Socioeconomic Potential of an Urban Enclave, Philadelphia: Temple UP, 1992.

[16] M. Zhou, Contemporary Chinese America: Immigration, Ethnicity, and Community Transformation, Philadelphia: Temple UP, 2009.

[17] F. Ng, The Taiwanese Americans, Westport: Greenwood, 1998.

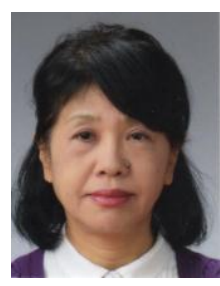

Masami Usui received her BA and MA degrees from Kobe College, Japan, and her second MA and Ph.D. degrees from Michigan State University. After teaching at Hiroshima University, she is currently a professor of English and the chair of graduate school of English at Doshisha University, Kyoto, Japan. She has been doing her research and writings on Virginia Woolf and women writers, Asian American literature and culture, and popular culture. She published papers in Japan, England, Korea, USA, Germany, etc., and contributed to Virginia Woolf and War in 1991, Asian American Playwrights in 2002, Literature in
English: New Ethnical, Cultural, and Transnational Perspective in 2013, Virginia Woolf and December 1910 in 2014, etc. Along with MLA International Virginia Woolf Conference, International Popular Culture Conference, American Studies Association Conference, she has presented her papers in English at Academia Senica in Taiwan, ASAK and KAFSEL in Korea, MESEA in Hungary, CISLE in Canada, International Conference on Asian American Expressive Culture in Beijing, China, International Conference: The Cultural Translation and East Asia, Bangor, England, The 20th Annual Conference of EALA in Taiwan, and International PC/ACS Conference in Poland, and the 2014 International Symposium on CrossCultural Studies, Taiwan, International Conference: English Studies as Archive and as Prospecting the 80th Anniversary Conference, University of Zagreb, Zagreb, Croatia, The 3rd International Conference on Linguistics, Literature and Culture 2014, Penang, Malaysia, Expanding the Parameters of Asian American Literature: An International Conference, Xiamen University, Xiamen, Fujian, China, and The CISLE 2015, Gottingen University, Germany. 